\title{
Racial differences in the incidence of colorectal cancer
}

\author{
Rukinder Virk $M B^{1}$, Sharlene Gill $M D^{2}$, Eric Yoshida $M D^{3}$, Simon Radley $M D^{4}$, Baljinder Salh $M B^{3,4}$
}

\begin{abstract}
R Virk, S Gill, E Yoshida, S Radley, B Salh. Racial differences in the incidence of colorectal cancer. Can J Gastroenterol 2010;24(1):47-51.
\end{abstract}

BACKGROUND: Colon cancer is one of the most common cancers and the second most common cause of cancer mortality in Western societies. Population screening has been introduced as a means to reducing its impact; however, there are little or no data on the incidence of this disorder in the different populations that comprise the Canadian population.

OBJECTIVE: To retrospectively determine the incidence of colorectal cancer in selected racial populations of British Columbia.

METHODS: The British Columbia Cancer Agency database was used to retrieve information on the incidence of cancers occurring during the years 1994 to 1998, with the British Columbia and national population censuses used to derive the age-specific and age-standardized incidence rates of colorectal cancers. Surnames were used to identify the origin of individuals from South Asian and Chinese backgrounds. RESULTS: For the Caucasian Canadian (C) population, the weighted age-standardized incidence rate ranged from 51.99 per 100,000 in 1995, to 57.68 per 100,000 in 1998. For Chinese Canadians (CC), the range was 39.2 per 100,000 in 1996 , to 31.2 per 100,000 in 1998 . For South Asian Canadians (SAC), the range was 7.40 per 100,000 in 1994 , to 24.85 per 100,000 in 1998 . The RR for the development of cancer were significantly different when comparing $\mathrm{C}$ versus $\mathrm{CC}$ ( $\mathrm{RR}$ 1.9; $95 \%$ CI 1.58 to $2.31 ; \mathrm{P}<0.001$ ), C versus SAC (RR $7.1 ; 95 \% \mathrm{CI}$ 4.20 to $12.0 ; \mathrm{P}<0.0001$ ) and $\mathrm{CC}$ versus SAC (RR 3.7; 95\% CI 2.14 to $6.5 ; \mathrm{P}<0.0001)$.

CONCLUSIONS: Significant differences in the incidence of colorectal cancers have been defined for the first time in various racial subgroups in British Columbia. This finding may have important implications for both screening and understanding of the environmental factors influencing the biology of these lesions. Because SAC have among the highest incidence of atherosclerotic heart disease and diabetes, it suggests that unidentified genetic and/or environmental protective factors are capable of countering the traditionally recognized risk of high saturated fat intake for the development of colorectal cancer.

\section{Les différences raciales dans l'incidence de cancer colorectal}

HISTORIQUE : Le cancer du côlon est l'un des cancers les plus courants et la deuxième cause de mortalité par le cancer en importance dans les sociétés occidentales. Le dépistage des populations a été mis en place pour en réduire les répercussions. Cependant, il existe peu de données, sinon aucunes, sur l'incidence de cette maladie dans les différentes populations qui composent la population canadienne.

OBJECTIF : Déterminer rétrospectivement l'incidence de cancer colorectal dans des populations raciales sélectionnées de la ColombieBritannique.

MÉTHODOLOGIE : Les auteurs ont utilisé la base de données de la British Columbia Cancer Agency pour extraire l'information sur l'incidence des cancers qui se sont produits entre 1994 et 1998, de même que les recensements de la population britanno-colombienne et nationale pour dériver le taux d'incidence de cancers colorectaux propres à l'âge et stratifiés selon l'âge. Les noms de famille ont permis d'établir l'identité des personnes d'origine sud-asiatique et chinoise.

RÉSULTATS : Chez les Canadiens de race blanche (B), le taux d'incidence pondéré et stratifié selon l'âge variait entre 51,99 cas pour 100000 habitants en 1995 et 57,68 cas pour 100000 habitants en 1998 . Chez les Canadiens d'origine chinoise (C), la plage variait entre 39,2 cas pour 100000 habitants en 1996 et 31,2 cas pour 100000 habitants en 1998 . Chez les Canadiens d'origine sud-asiatique (A), la plage variait entre 7,40 cas pour 100000 habitants en 1994 et 24,85 cas pour 100000 habitants en 1998 . Le rapport de risque (RR) d'apparition de cancer était significativement différent lorsqu'on comparait les $\mathrm{B}$ aux $\mathrm{C}$ (RR 1,9; $95 \%$ IC 1,58 à 2,31; $\mathrm{P}<0,001$ ), les $\mathrm{B}$ aux $\mathrm{A}$ (RR 7,1; $95 \%$ IC 4,20 à 12,0; $\mathrm{P}<0,0001$ ) et les $\mathrm{C}$ aux $\mathrm{A}$ (RR 3,7; 95 \% IC 2,14 à 6,5; $\mathrm{P}<0,0001$ ).

CONCLUSIONS : Pour la première fois, on a défini des différences significatives dans l'incidence de cancers colorectaux au sein de diver sous-groupes raciaux de la Colombie-Britannique. Cette observation peut avoir des conséquences importantes pour le dépistage et la compréhension des facteurs environnementaux qui influent sur la biologie de ces lésions. Puisque les A ont la plus forte incidence de cardiopathie athéroscléreuse et de diabète, ces résultats laissent supposer que des facteurs protecteurs génétiques ou environnementaux non identifiés peuvent contrer le risque habituellement reconnu de consommation de graisses très saturées pour l'apparition de cancer colorectal.

Key Words: Colon cancer; Incidence; Race

Colorectal cancer is a major cause of morbidity and mortality in Western countries. It is the fourth most common cause of cancer in the world (1) and in British Columbia (2). There are well-defined risk factors including genetic syndromes (eg, familial adenomatous polyposis, hereditary nonpolyposis colon cancer), inflammatory bowel disease and a family history of colon cancer, which are known to predispose susceptible individuals to developing this disease (3). Furthermore, racial and ethnic disparities exist in the incidence, mortality and clinical trends of colorectal cancer (4). Studies investigating incidence rates among different ethnic groups have shown that compared with the residents of western Europe, North America and Australia, those in

${ }^{1}$ Department of Anaesthesia, Leeds University Hospital, Leeds, United Kingdom; ${ }^{2}$ Department of Medical Oncology, British Columbia Cancer Agency; ${ }^{3}$ Division of Gastroenterology, University of British Columbia, Vancouver, British Columbia; ${ }^{4}$ Department of Surgery, University of Birmingham, Birmingham, United Kingdom

Correspondence and reprints: Dr Baljinder Salh, University of British Columbia, 5th Floor, 2775 Laurel Street, Vancouver, British Columbia

V5Z 1M9. Telephone 604-875-5287, fax 604-875-5447, e-mail bsalh@interchange.ubc.ca

Received for publication February 18, 2009. Accepted May 28, 2009 
Africa, South Asia and Latin America have a lower incidence of colorectal cancer (5). The incidence in native Chinese is significantly lower than in Chinese-Americans, who themselves have rates similar to Americans. This geographical variation in the incidence of the disease, and the pattern of increased incidence in migrants from low- to high-risk areas, suggests a major contribution from environmental factors. This is further supported by the fact that most populations with low risks of colon cancer also have low risks of heart disease. Indeed, certain dietary components related to high socioeconomic status, specifically, animal fat and red meat, and physical inactivity, have been associated with this disease $(6,7)$. To what extent these factors play a role in the etiology of colorectal cancer in ethnic minorities remains to be fully elucidated because risk factor data for this disease are scarce in these populations. However, evidence suggests that dietary constituents peculiar to a typical Western diet may affect colorectal carcinogenesis in various ethnic minority groups (4).

The few studies that have investigated the incidence of colorectal cancer in the South Asian population living in the West are somewhat limited in terms of using small sample sizes $(8,9)$. They also seem to overlook the fact that South Asians, similar to Caucasians, comprise multiple subgroups, each with a unique set of genetic and cultural characteristics; grouping them into broad categories could mask some important differences. Studies on colorectal cancer mortality show that certain races, such as AfricanAmericans, have higher mortality rates than Caucasians (10). Various hypotheses have been proposed for these trends; however, no mechanisms have been substantiated.

There is evidence to suggest that discrepancies exist in the anatomical characteristics of colorectal cancer among different ethnic groups $(11,12)$. A study (11) comparing the profile of colorectal cancer between ethnic Chinese and Caucasians in a Vancouver (British Columbia) community hospital, showed that the two groups were similar except in the laterality of colonic tumours, with a greater propensity for the left side among the Chinese. This difference was believed to be genetic, because the trend persisted independently of length of stay in Canada. We hypothesized that similar trends may exist in other ethnic groups, and that this may prove helpful in future screening strategies. The present study had three main objectives: to determine absolute and relative incidence rates of colorectal cancer among three broad ethnic groups (South Asian Canadians [SAC], Chinese Canadians [CC] and Caucasian Canadians [C]); to analyze and compare case fatality rates in these groups; and to compare the clinical characteristics of colorectal cancer. This may provide preliminary data for the examination of causative or protective factors associated with this disease. Differences in case fatality rates, if they exist, may help to guide future research investigating discrepancies in the presentation, stage at diagnosis and treatment, as well as prognosis for ethnic minorities. Our initial hypothesis was that a significantly lower incidence rate would be observed in the SAC group than in the CC or C groups, concordant with previous studies. We did not anticipate finding differences in the clinical profile of colorectal cancer among ethnic groups and, therefore, adopted the null hypothesis.

\section{METHODS}

In 1996, British Columbia had a total population of 3,724,500. The age distribution of the population was $32.7 \%$ younger than 24 years of age, $32.8 \%$ between 25 and 44 years, $21.8 \%$ between 45 and 64 years and $12.7 \%$ were 65 years of age and older. The male to female ratio was approximately the same in all age groups, ranging from 0.92:1 to $1: 1$. Those of European ancestry (grouped with C) comprised $82.1 \%$ of the total population, CC $10.00 \%$ (Chinese $8.5 \%$ and, for the purpose of this study, Japanese $0.9 \%$ and Vietnamese $0.6 \%$ were included) and South Asians $4.5 \%$ (predominantly Sikh 4.3\%, Pakistani/Ismaili 0.1\%, South Asian unspecified $0.1 \%)$.

All cases of colorectal cancer were identified from the British Columbia Cancer Registry and were subjected to the following criteria: diagnosis of invasive adenocarcinoma of the colon and/or rectum (International Classification of Diseases - 9th Revision for oncology site between codes C18 and C20.9 inclusive), and receiving a diagnosis as a British Columbia resident between 1994 and 1998 inclusive.

Data regarding the following were requested for all cases: names (surname, first and second names), sex, birth date, age at diagnosis, age at death, cause of death, tumour site and histology of tumour for all cases. Ethnicity was determined indirectly using the patients' names as indicators of their ethnic origin. This method has been found to be a reliable guide to ethnic origin and has also been used in previous studies (13). In the event of a surname being equivocal (eg, 'Lee' could be either Caucasian or Oriental), the first and second names were used. Generally, all three names were carefully scrutinized. Ethnic groups were classified as SAC (including Punjabi, Hindi and Ismaili/Pakistani Muslim) and CC (Chinese, Japanese, Vietnamese or Korean). The remainder were classified as $\mathrm{C}$ by exclusion. Two researchers carefully scrutinized all names independently. After data collection, disagreements regarding ethnic origin were resolved by discussion. Two independent volunteers of the relevant ethnic groups confirmed the selected names as being either Pakistani or Middle Eastern (Iranian), the latter being excluded from the study (nine subjects). It is important to note that Native/ Aboriginal North Americans were not separately assigned based on this methodology and were incorporated into the $\mathrm{C}$ group.

Incidence data were calculated for colorectal cancer as follows: Age-specific incidence rates (ASR) for SAC, CC and C separately, were calculated by using the number of cases in a single year as the numerator and the total age-specific population for the relevant ethnic group in British Columbia as the denominator. Weighted age-standardized data were estimated for each ethnic group by multiplying the ASR by the proportional representation of that group from the British Columbia census (Table 1, see footnote). For example, there were 427 cases in the ' $C$ ' category, for the 45 to 64 years age group in 1994. Because there were 669,030 individuals in that age group, this gave an ASR of 63.82 per 100,000 population. Given that this group accounted for $22 \%$ of the population, the weighted age-standardized incidence rate is $63.82 \times 0.22$, yielding a rate of 14.04 per 100,000 .

The number of individuals in each age group was derived from a combination of both the British Columbia (14) and national (15) census data. This method was used because no age distribution data were available for the visible minorities of British Columbia. For example, the SAC group was comprised of East Indians, Punjabis, Pakistanis as well as South Asians not included elsewhere, giving a value of 169,512 for British Columbia in 1996 (14). For the older than 65 years of age group, nationally, there were 36,930 individuals of a total of 670,590 SAC (15), yielding an approximate percentage of $5.5 \%$. This number was multiplied by 169,512 to obtain 9335 individuals in the older than 65 years of age group, as shown in Table 1 (another example is provided in the table footnote).

Relative incidence rates were calculated using the $\mathrm{C}$ population as the control, with the uncorrected $\chi^{2}$ test (using Yates correction) used to estimate the significance of relative incidence rates for each age group (Table 2). 
Incidence rates of colorectal cancer in British Columbia 1994 to 1998

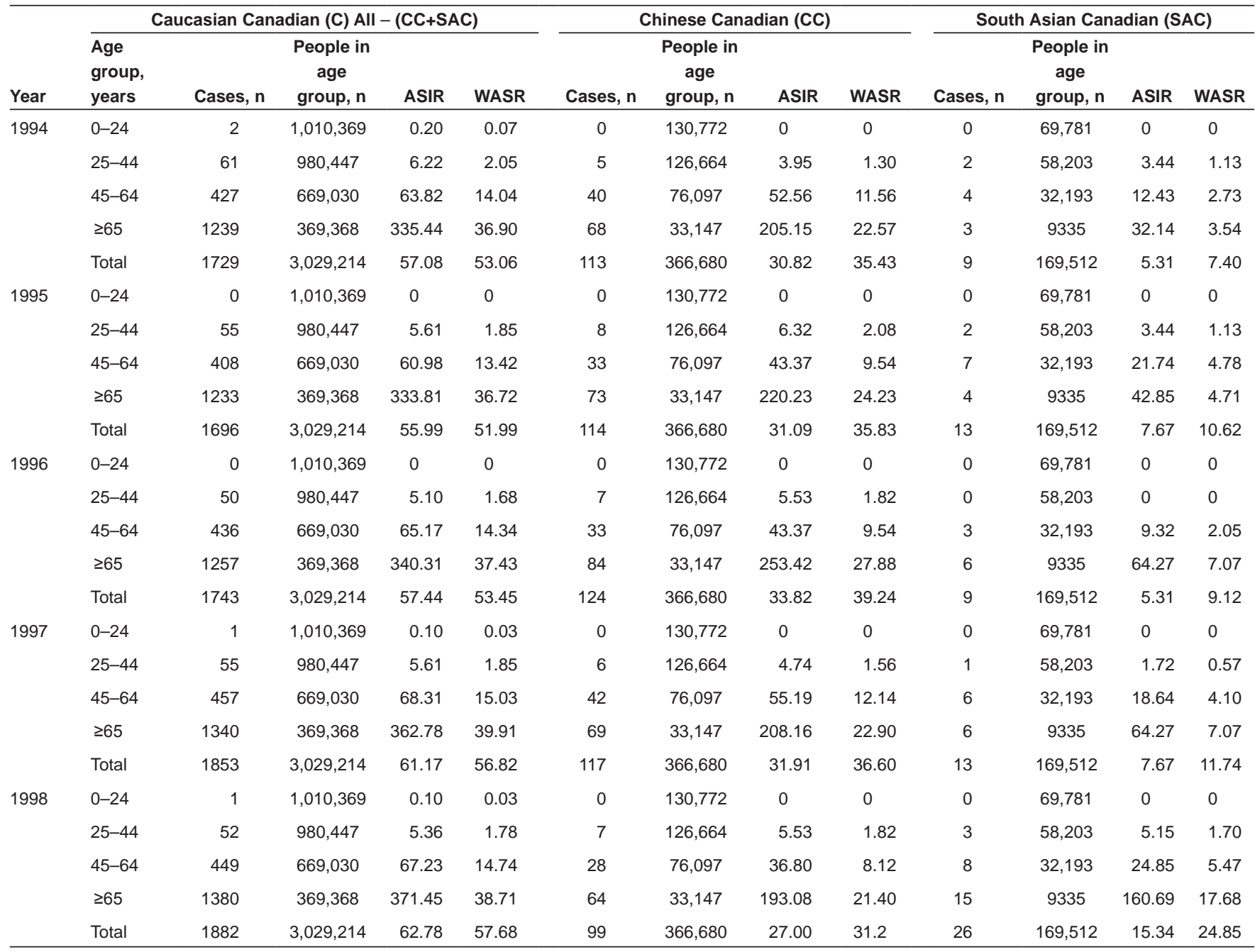

Age distribution of colorectal cancer rates for the years 1994 to1998. The data are derived from the total number of cases in each age group (column 3), which are then divided by the number in that group in the British Columbia (BC) population (column 4, taken from the 1996 census profile of BC), to give the age-specific incidence rate (ASIR) for that age group (column 5). Subsequently, the weighted age-standardized incidence rate (WASR) was calculated by multiplying the agespecific rate by the following numbers: $0-24$ years: $0.34 ; 25-44$ years: $0.33 ; 45-64$ years: 0.22 ; $\geq 65$ years: 0.11 . These proportions indicate the relative contribution of that age group to the total population of $B C$ (the sum of these equals 1). The age-specific population for each ethnic group was determined using both the data from the BC statistics for 1996, which provided the total number of individuals in each group (eg, C: 3,029,214, CC: 366,680, SAC: 169,512 [14]), and the proportion of individuals in each ethnic group, for each age category, from the 1996 national census tables (15). For example, 3,029,214 individuals were in the 'all others' category reflecting the $C$ group in the 1996 BC census. For the numbers in the age distribution 0-24 years in BC, this figure was multiplied by 8,448,825/25,330,645 (number of individuals in that age group divided by the total Canadian population, taken from the national census), the answer, 1,010,369, is shown in the table

Additionally, mortality rates for colorectal cancer were determined for each ethnic group for individual years 1994 to 1998, by using the number of deaths from colorectal cancer as the numerator and the total population of each ethnic group as the denominator. These rates were then expressed as ratios to the incidence rates to give case fatality rates (Table 3 ).

The following parameters were analyzed by univariate analysis and the $\chi^{2}$ test: anatomical distribution (eg, colon or rectum), laterality (colon tumours were classified as right sided if arising from the cecum up to the transverse colon, left sided if located from the splenic flexure down to the rectum) and male to female ratio.

SPSS (SPSS Inc, USA) for Windows (Microsoft Corporation, USA) was used to aid in the analysis of data throughout the present study.

\section{RESULTS}

A total of 9549 cases of colorectal cancer, as defined by the set criteria, were reported to the British Columbia Cancer Agency from 1994 to 1998. Of these, 8903 (93\%) occurred in C, 567 (6\%) in CC , and $70(0.5 \%)$ in SAC. The remaining nine were excluded (Middle Eastern origin [eg, Iranian]).

\section{ASR for colorectal cancer}

The data indicate a highly consistent pattern of colorectal cancer incidence in consecutive years from 1994 to 1998 (Table 1). As expected, inspection of the $\mathrm{C}$ population revealed that the vast majority of patients (more than 70\%) were older than 65 years of age. However, it is also apparent that there was a significant number of patients - approximately 60 per year (approximately 3\% of 
TABLE 2

RR for colon cancer incidence among Canadians (C), Chinese Canadians (CC) and South Asian Canadians (SAC)

\begin{tabular}{|c|c|c|c|c|c|c|}
\hline \multirow[b]{2}{*}{ Group } & \multirow[b]{2}{*}{ Cases/year, n } & \multirow{2}{*}{$\begin{array}{c}\text { Mean } \\
\text { incidence/100,000/year }\end{array}$} & \multicolumn{4}{|c|}{ Comparison } \\
\hline & & & Groups & RR & $95 \% \mathrm{Cl}$ & $\mathbf{P}$ \\
\hline $\mathrm{C}$ & 1780 & 58.9 & $\mathrm{C}$ versus $\mathrm{CC}$ & 1.9 & $1.58-2.31$ & $<0.001$ \\
\hline $\mathrm{CC}$ & 113 & 30.8 & $C$ versus SAC & 7.1 & $4.20-12.0$ & $<0.0001$ \\
\hline SAC & 14 & 8.3 & CC versus SAC & 3.7 & $2.14-6.5$ & $<0.0001$ \\
\hline
\end{tabular}

$R R$ comparisons between the different groups determined using the $\chi^{2}$ test with Yates' correction. The number of cases per year figure is derived from the total number of cases for each group divided by 5 (number of years examined). Significantly increased rates were observed in the $C$ and CC groups compared with the SAC group

TABLE 3

Case fatality rate (CFR) for colorectal cancers, 1994 to 1998

\begin{tabular}{|c|c|c|c|c|c|c|c|c|c|}
\hline \multirow[b]{2}{*}{ Year } & \multicolumn{3}{|c|}{ Caucasian Canadian } & \multicolumn{3}{|c|}{ Chinese Canadian } & \multicolumn{3}{|c|}{ South Asian Canadian } \\
\hline & Deaths, $n$ & Cases, $n$ & CFR & Deaths, $n$ & Cases, $\mathbf{n}$ & CFR & Deaths, $n$ & Cases, $\mathrm{n}$ & CFR \\
\hline 1994 & 206 & 1729 & 0.12 & 20 & 113 & 0.18 & 0 & 9 & 0 \\
\hline 1995 & 446 & 1696 & 0.26 & 23 & 114 & 0.20 & 1 & 13 & 0.08 \\
\hline 1996 & 517 & 1743 & 0.30 & 36 & 124 & 0.29 & 2 & 9 & 0.22 \\
\hline 1997 & 623 & 1853 & 0.34 & 39 & 117 & 0.33 & 5 & 14 & 0.38 \\
\hline 1998 & 628 & 1881 & 0.33 & 32 & 99 & 0.32 & 8 & 26 & 0.31 \\
\hline
\end{tabular}

CFRs were calculated by dividing the number of deaths by the number of cases for a given year. They appear to be comparable among the three groups with some outliers likely related to small sample sizes (eg, SAC data for 1994) or simply due to chance (eg, C data for 1994)

TABLE 4

Comparison of the incidence rates between different groups from previously published studies and current study

\begin{tabular}{|c|c|c|c|}
\hline \multirow{2}{*}{$\begin{array}{l}\text { Author (reference) } \\
\text { [country, years investigated] }\end{array}$} & \multicolumn{3}{|c|}{$\begin{array}{l}\text { Group incidence rate } \\
\text { (cases/100,000/year) }\end{array}$} \\
\hline & w & CC & SAC \\
\hline $\begin{array}{l}\text { Gee and Mayberry (8) } \\
\text { [Leicester, United Kingdom, 1981-1995] }\end{array}$ & 55.3 & ND & 8.9 \\
\hline $\begin{array}{l}\text { Blesch et al (16) } \\
\text { [USA, SEER, 1988-1991] }\end{array}$ & 43.5 & ND & 16.7 \\
\hline $\begin{array}{l}\text { Jain et al (17) } \\
\text { [California, USA, 1998-2000] }\end{array}$ & 55.4 & 46.3 & 35.1 \\
\hline $\begin{array}{l}\text { Whittemore (19) } \\
\text { [British Columbia, 1978-1982] }\end{array}$ & 34.4 & 34.4 & ND \\
\hline $\begin{array}{l}\text { Virk et al (present study) } \\
\text { [British Columbia, 1994-1998] }\end{array}$ & 58.9 & 30.8 & 8.3 \\
\hline
\end{tabular}

Table compares the rates of cancer from the present study with those from previously published work. Overall, the rates are relatively consistent for nonHispanic Caucasians in the USA, and the English or Canadian populations for the other pieces of data $(W)$. Interestingly, there appears to be a much closer gap between the different populations in the data from the Jain et al (17) study from California, USA. CC Chinese Canadian; ND Not determined; SAC South Asian Canadian; SEER Surveillance, Epidemiology and End Results

the total) - who were younger than 45 years of age. Although not significantly different, the CC population had a greater proportion (between $30 \%$ to $40 \%$ of the total) who were younger than 45 years of age. For the SAC population, the range was even wider $-33 \%$ to nearly $70 \%$ fell into this category. Interestingly, there was an increase in the incidence of colorectal cancer for the SAC group from 1997 to 1998.

Significantly, the data in Table 2 indicate a hierarchical pattern to the ASR of colon cancer, with the highest levels seen in C, followed by CC and SAC. To our knowledge, this trend has not been previously demonstrated in any population.

Case fatality rates for colorectal cancer

In contrast, case fatality rates were inconsistent over the five-year study period for all groups, which appears to increase from 1994 to 1997, then plateaus from 1997 to 1998 (Table 3). There were no differences in the manner of clinical presentation among the CC, $\mathrm{SAC}$ and $\mathrm{C}$ groups.

Profile of colorectal cancer in the different ethnic groups Results for the male to female ratio of colorectal cancer show results ranging from 1.8:1 in SAC, 1.3:1 in CC and 1.2:1 in C. There were no significant differences in anatomical distribution of colorectal cancers among the groups.

\section{DISCUSSION}

The present study was the first to definitively examine the incidence of colorectal cancer across major demographic groups in Canada. We used individuals' surnames to examine this parameter in the SAC and CC groups, in comparison with the $\mathrm{C}$ group, comprising the unique population mix in British Columbia. Our data generally support findings from previous studies (Table 4), revealing significantly reduced incidence rates in SAC compared with $\mathrm{C}$ reported from England (8) and North America (16,17), with CC having intermediate values. The lower incidence rates in the CC population surprisingly contradict the findings of some previous studies that show the incidence rates of Chinese immigrants to be similar to that of Caucasian populations of European descent (18). In particular, one study (19) reported that the incidence of colon cancer in older Chinese men was as high as in the Caucasian population of the western United States and Canada. It is plausible that errors in the study methods relating to the use of broad, heterogeneous ethnic groups may have affected interpretation of the data. It is unlikely that such a scenario accounted for our observation because the Chinese were undoubtedly the largest subpopulation in the CC group and, therefore, had a greater influence on the results. The fact that the incidence rates were consistent with time, and that both the SAC and CC had incidence rates well below the mean rates for $\mathrm{C}$, strengthens the significance of our findings.

Case fatality rates for all groups were inconsistent over consecutive years and appear to show a pattern of increasing mortality. This unexpected result may be due to chance, especially because a relatively crude methodology was used to investigate case fatality rates. It is unlikely that the behaviour of the cancers differed between groups. 
Analysis of the male to female incidence ratios reveals no statistically significant differences, although the ratio was highest in the SAC group; the reasons for this may include different dietary practices, migration or a genuine difference in the incidence pattern.

A study from a small community hospital in British Columbia (11) showed an interesting trend in the laterality of tumours. However, our larger data set failed to confirm the propensity toward left-sided tumours reported in the CC population.

Determining the ethnic origin of subjects in the SAC population may have introduced selection bias in our methods. Undoubtedly, the accuracy of this method depends on the knowledge and experience of the researchers responsible for classifying individuals into ethnic groups and the characteristics of the names themselves. People can adopt names belonging to other cultures, although this is probably more relevant in younger generations. Furthermore, people from mixed-race backgrounds were likely to have been missed by the name analyzers because their names were not likely to be representative. Although fraught with inaccuracy, this was the best method to use, because ethnic origin is not routinely recorded for cancer statistics in British Columbia.

Confounding could be another major issue. Confounding by age was eliminated by the use of age-standardized rates. Sexstandardized rates, in addition, would have excluded the influence of sex. Unfortunately, as mentioned, there are no data for this parameter for individual ethnic groups.

Lifestyle is known to have a significant impact on the incidence and type of tumours that develop. This is exemplified by the increasing incidence of 'Western malignancies' at alarming rates in Inuit populations who, traditionally, have low incidence rates of breast, lung and colon tumours (20). The increased incidence has been attributed to sedentary lifestyles, smoking, consumption of imported processed foods and poorly characterized reproductive factors.

The low incidence rates found in SAC and CC lay the foundation for future work examining the effects of lifestyle and environment on the incidence of colorectal cancer in ethnic minorities.

\section{REFERENCES}

1. Borugian MJ, Sheps SB, Whittemore AS, Wu AH, Potter JD, Gallagher RP. Carbohydrates and colorectal cancer risk among Chinese in North America. Cancer Epidemiol Biomarkers Prev 2002;11:187-193.

2. <http://www.bccancer.bc.ca/HPI/CancerStatistics/FF/default.htm> (Version current at December 10, 2009).

3. Kumar P, Clark M, eds. Clinical medicine, 4th edn. W.B. Saunders, London, 1998:273-4.

4. Baquet CR, Commiskey P. Colorectal cancer epidemiology in minorities: A review. J Assoc Acad Minor Phys 1999;10:51-8.

5. Lee MP, Gourley L, Duffey SW, Esteve J, Lee J, Day LE. Colorectal cancer and diet in an Asian population - a case-control study among Singapore Chinese. Int J Cancer 1989;43:1007-16.

6. Willett WC. Goals for nutrition in the year 2000. CA Cancer J Clin 1999;49:331-52.

7. Hsing AW, McLaughlin JK, Chow WH, et al. Risk factors for colorectal cancer in a prospective study using U.S. white men. Int J Cancer 1998;77:549-53.

8. Gee IR, Mayberry JI. A study of colorectal cancer in the Asian and European population in the city of Leicester from 1981 to 1991. Pub Health 2000;114:53-9.

9. Potter JF, Dawkins DH, Pantha HS, Beevers DG. Cancer in Blacks, Whites and Asians in a British hospital. J Royal Coll Phys 1984:4:231-5

10. Marcella S, Miller JE. Racial differences in colorectal cancer mortality - the importance of stage and socioeconomic status. J Clin Epidemiol 2001;54:359-66.
Eventually, it is possible that incidence rates will equalize among these three groups, a point best illustrated by the data from California (USA) (17). The SAC group in this particular study reported rates of colorectal cancer that are among the highest for this group in all of the studies reported to date. It is possible that the assumption of a Western lifestyle and diet has occurred most readily in this group compared with individuals residing in either the United Kingdom or Canada. The data for the CC group in the same study indicate a very similar phenomenon. The ASR for colorectal cancer in China is reported to be 13.6 for men and 9.2 for women (21). This is clearly much lower than the figures reported in the studies shown in Table 4. Again, the ASR for the CC group in California (46.3) appears to be higher than the figure in British Columbia (30.8) determined in the present study. Unfortunately, we are not aware of any data from the United Kingdom to compare this particular item with.

The findings from the present study may have some relevance in the design of screening strategies for this important clinical problem. Because rates are much lower in SAC, perhaps an approach involving fecal occult blood testing as the first-line screening modality would be the most efficient. Equally, the findings may be supportive of the need to examine a return to a diet comparable with that of the country of origin (less saturated fat, more fibre) to reduce the incidence of colorectal cancer in migrating populations, as well as that of those already residing in the destination country.

ACKNOWLEDGEMENTS: The following contributors provided invaluable input to make this study possible: Wendy Robb, who supplied the data from the British Columbia Cancer Agency, Dr Greg Hislop (British Columbia Cancer Agency) for helpful discussions, Tom Marshall and Louise Hiller who provided statistical support, and Nazneen Begum and Abdulrahman Al Fares, who analyzed some of the names.

11. Taylor RH, Moffett FJ. Profile of colorectal cancer at a community hospital with a multiethnic population. Am J Surg 1994;167:509-12.

12. Chatter CD, Onime GD, Valentine IS, Cudjae E, Rivera L. Colorectal cancer in a multi-ethnic urban group: Its anatomical and age profile. Int J Surg 2000;85:137-42.

13. Gill S, Shah A, Le N, Cook EF, Yoshida EM. Asian-ethnicity related differences in gastric cancer. Presentation and outcome among patients treated at a Canadian cancer centre. J Clin Oncol 2003;21:2070-6.

14. <http://www.bcstats.gov.bc.ca/data/cen96/bc96cen.pdf> (Version current at November 19, 2009).

15. Statistics Canada. 1996 National tables: Visible minority by age. <www.statcan.ca> (Version current at November 19, 2009).

16. Blesch KS, Davis F, Kamath SK. A comparison of breast and colon cancer incidence rates among Native Asian Indians, US immigrant Asian Indians, and whites. J Amer Diet Assoc 1999;10:1275-7.

17. Jain RV, Mills PK, Parikh-Patel A. Cancer incidence in the South Asian population of California. J Carcinogen 2005;4:21-33.

18. Gallagher RP, Elwood JM. Cancer mortality among Chinese, Japanese, and Indians in British Columbia, 1964-73. Natl Cancer Inst Monogr 1979;53:89-94.

19. Whittemore AS. Colorectal cancer incidence among Chinese in North America and the People's Republic of China: Variation with sex, age and anatomical site. Int J Epidemiol 1989;18:563-8.

20. Friborg JT, Melbye M. Cancer patterns in Inuit populations. Lancet Oncol 2008;9:892-900.

21. Parkin DM, Bray F, Ferlay J, Pisani P. Global cancer statistics, 2002. CA Cancer J Clin 2005;55:74-108. 


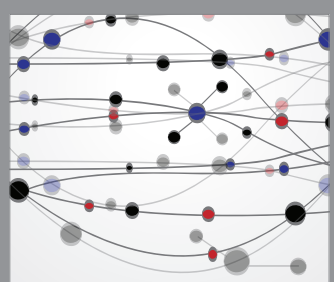

The Scientific World Journal
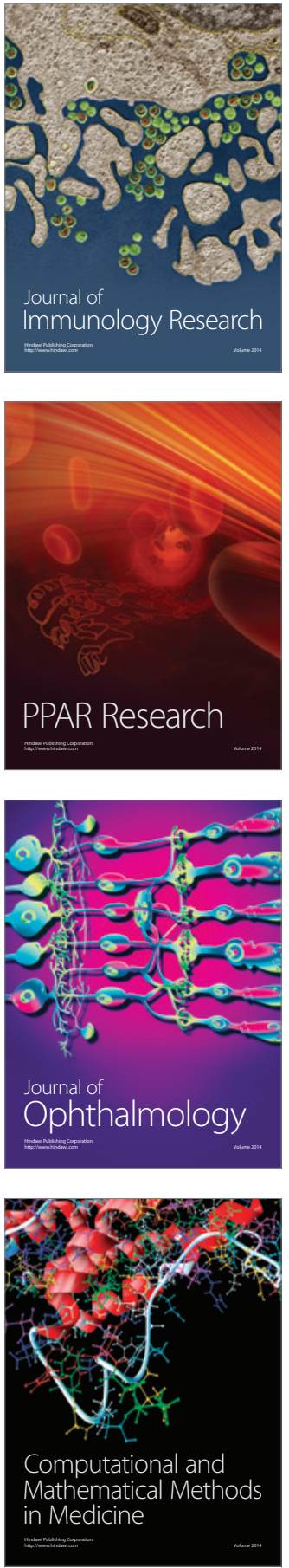

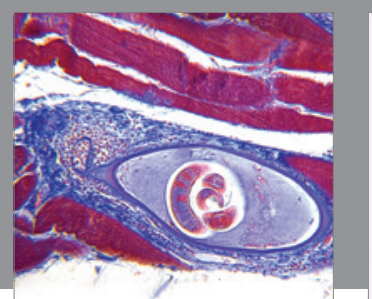

Gastroenterology Research and Practice

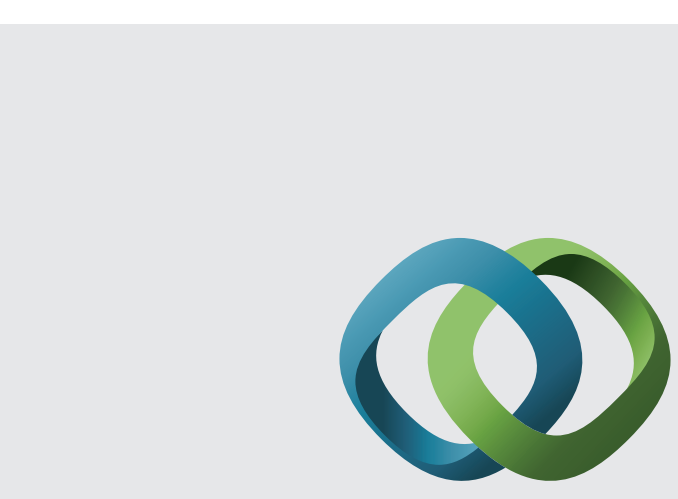

\section{Hindawi}

Submit your manuscripts at

http://www.hindawi.com
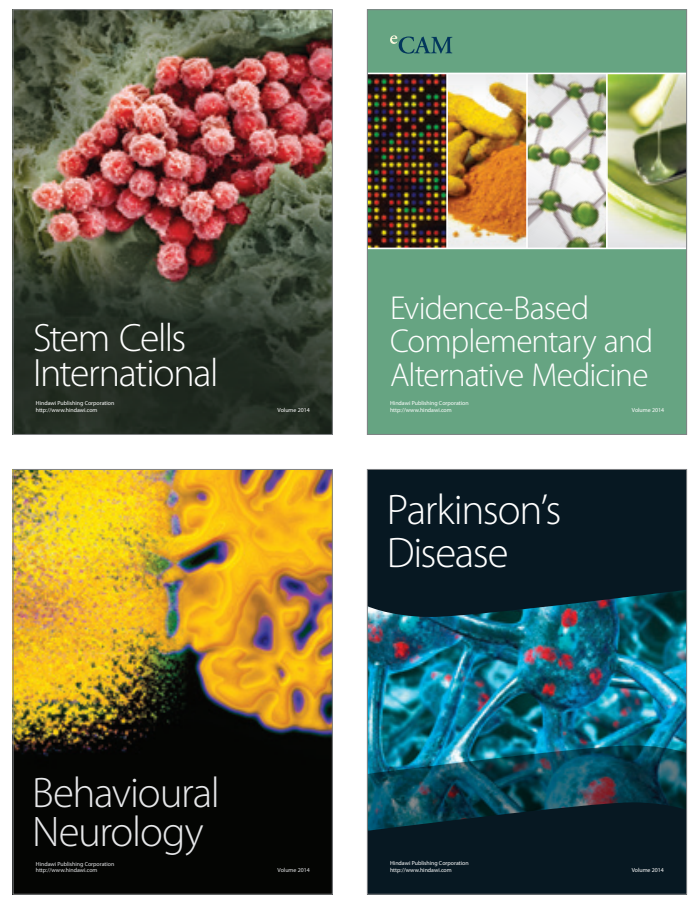
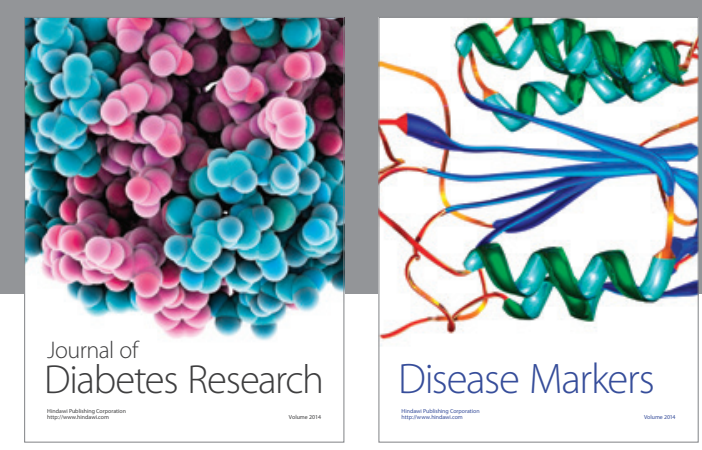

Disease Markers
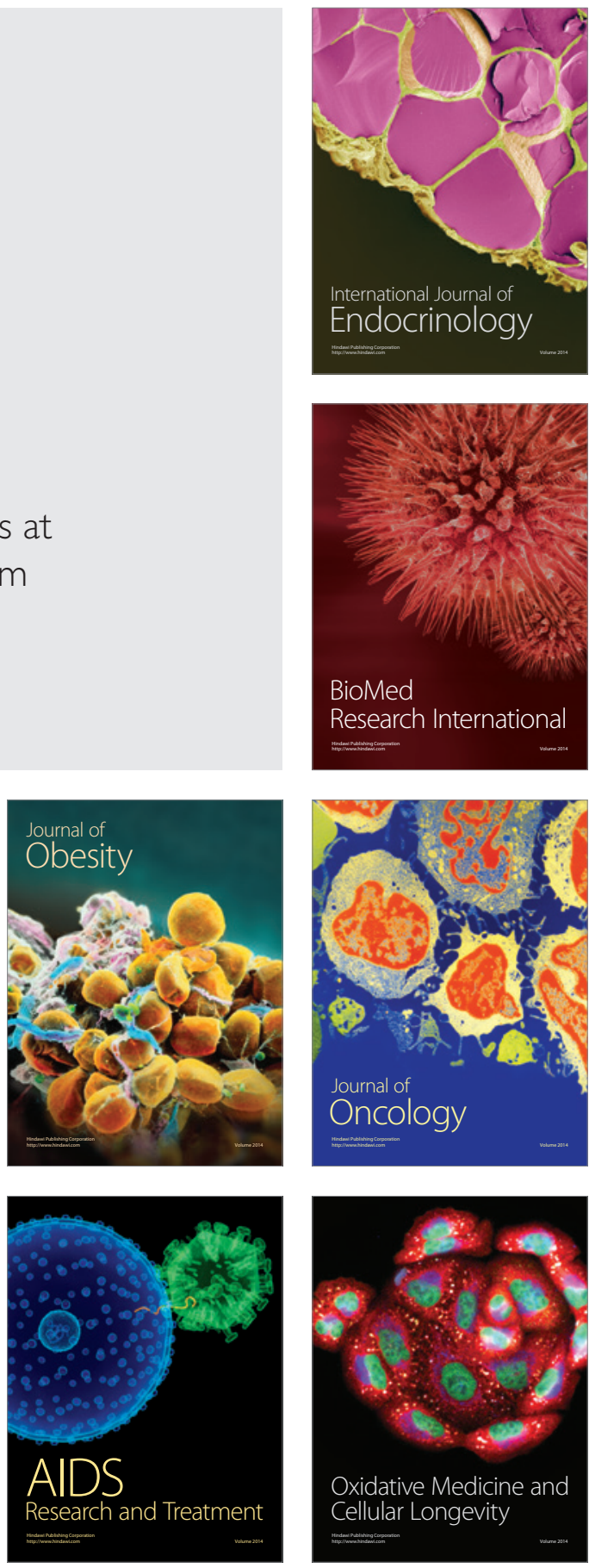